\title{
Quality of Life and Its Determinants of Hemodialysis Patients in Taiwan Measured With WHOQOL-BREF(TW)
}

\author{
Shu-Chang Yang, MD, Pei-Wen Kuo, MPH, Jung-Der Wang, MD, Ming-I Lin, MS, and Syi Su, PhD
}

- Background: In 1991, the World Health Organization (WHO) initiated a cross-cultural project to develop a quality-of-life (QOL) questionnaire (WHOQOL); soon after this, the clinically applicable short form was developed and named WHOQOL-BREF, followed by a Taiwanese version (WHOQOL-BREF[TW]). Methods: We first administered the WHOQOL-BREF(TW) and symptom/problem scale to 376 patients with end-stage renal disease on regular hemodialysis therapy in Taiwan. Analysis with multiple stepwise regressions was conducted to study determinants of QOL domains and items. Results: The WHOQOL-BREF(TW) was reliable and valid from various validation studies. The 4 domains (physical, psychological, social relations, and environment) and global items (overall quality of life and general health) of the WHOQOL-BREF(TW) each differentiated symptoms/problems of hemodialysis patients from age-, sex-, and education-matched healthy referents. The 4 domains, except for environment and global items of the WHOQOL-BREF(TW), each differentiated erythropoietin dosage from age-, sex-, and educationmatched healthy referents. After adjusting for age, sex, marriage, and education, the prominent associated factors of various QOL domains and items were age, area (Taipei or Keelung), hemoglobin level, normalized protein catabolic rate, and symptom/problem scale. Conclusion: The WHOQOL-BREF(TW) is reliable and valid for longterm study of hemodialysis patients, and hemodialysis had negative impacts on QOL, especially in patients with more severe disease with greater symptom/problem scores, lower hemoglobin levels, and lower normalized protein catabolic rates. Am J Kidney Dis 46:635-641.

(C) 2005 by the National Kidney Foundation, Inc.

INDEX WORDS: End-stage renal disease (ESRD); hemodialysis (HD); quality of life; validation; World Health Organization Quality-of-Life Questionnaire (WHOQOL).

$\mathbf{Q}$ UALITY OF LIFE (QOL) is being used increasingly as an important parameter of health and well-being. QOL per se is an important outcome representing a person's concerns. QOL also is an important indicator of other outcomes, such as mortality and hospitalization. ${ }^{1}$ There are several reasons that QOL study is emerging in prevalent patients with end-stage renal disease (ESRD) undergoing hemodialysis (HD). The prevalence of patients with ESRD on HD therapy is still increasing. ${ }^{2,3}$ Although HD therapy prolongs life, there often is a significant diminution in QOL. ${ }^{2}$ ESRD is a chronic disease associated with many comorbidities and complications. ${ }^{3}$ Not surprisingly, these comorbid conditions adversely influence many aspects of QOL in HD patients. ${ }^{4}$

In 1991, the World Health Organization (WHO) initiated a cross-cultural project to develop a QOL questionnaire (WHOQOL) for generic use and defined QOL as "individuals' perceptions of their position in life in the context of the culture and value systems in which they live, and in relation to their goals, expectations, standards, and concerns." 5 Soon after this standard long form, the clinically applicable short form was developed and named WHOQOL-BREF. ${ }^{6,7}$ Although a variety of generic and diseasespecific instruments, such as the 36-Item Short-
Form Health Survey, Kidney Disease Quality-ofLife questionnaire, and Kidney Disease Questionnaire, had been developed and applied to the assessment of QOL in patients with ESRD, crossculture and cross-disease comparability were lacking. ${ }^{8} 9$ Therefore, the Taiwan version of the WHOQOL-BREF (WHOQOL-BREF[TW]) was developed for clinical use. ${ }^{10}$

The aim of our study is to first assess the reliability and validity of the WHOQOL$\mathrm{BREF}(\mathrm{TW})$ in HD patients, compare scores of

From the Institutes of Health Care Organization Administration and Occupational Medicine and Industrial Hygiene, College of Public Health, National Taiwan University; and Department of Internal Medicine, National Taiwan University Hospital, Taipei, Taiwan, ROC.

Received November 29, 2004; accepted in revised form June 13, 2005.

Originally published online as doi:10.1053/j.ajkd.2005.06.015 on September 7, 2005.

Supported in part by grant no. NHRI-EX94-9204PP from the National Health Research Institutes.

Address reprint requests to Syi Su, PhD, Institute of Health Care Organization Administration, College of Public Health, National Taiwan University, Rm 1512, No. 1, Section 1, Ren-ai Rd, Jhongjheng District, Taipei, Taiwan, ROC.E-mail: susyi1@ha.mc.ntu.edu.tw

(C) 2005 by the National Kidney Foundation, Inc.

0272-6386/05/4604-0008\$30.00/0

doi:10.1053/j.ajkd.2005.06.015 
QOL measured by means of the WHOQOL$\mathrm{BREF}(\mathrm{TW})$ between groups of HD patients and age-, sex-, and education-matched healthy referents, and identify major determinants of QOL in HD patients under a multiple regression model in which one may be able to quantify more detailed QOL changes independently attributed to a favorable outcome of HD.

\section{METHODS}

\section{Subjects}

In February 2002, we enrolled as many patients with ESRD who were undergoing regular $\mathrm{HD}$ at the dialysis centers of 13 regional hospitals or outpatient clinics in metropolitan Taipei and Keelung city as possible to participate in the study. In the end, 513 patients were enrolled. Patients with ESRD with a creatinine clearance less than 5 $\mathrm{mL} / \mathrm{min}(<0.08 \mathrm{~mL} / \mathrm{s})$ or a creatinine concentration greater than $8.0 \mathrm{mg} / \mathrm{dL}(>707 \mu \mathrm{mol} / \mathrm{L})$ were given first priority for HD therapy. Other patients with ESRD were eligible to receive HD if their creatinine clearance was less than 15 $\mathrm{mL} / \mathrm{min}(<0.25 \mathrm{~mL} / \mathrm{s})$ or creatinine concentration was greater than $6.0 \mathrm{mg} / \mathrm{dL}(>530 \mu \mathrm{mol} / \mathrm{L})$ and they had at least 1 of the following complications: congestive heart failure, pulmonary edema, pericarditis, a propensity for bleeding, mental status changes, seizures, peripheral neuropathy, persistent hyperkalemia, refractory nausea and vomiting, intractable metabolic acidosis, cachexia, or a blood urea nitrogen level greater than $100 \mathrm{mg} / \mathrm{dL}$ (>36 mmol/L). Voluntary informed consent was obtained from all invited patients.

To evaluate test-retest reliability, 20 patients in stable condition were selected and invited for retest. All these patients received a retest 4 to 8 weeks later. Patients with mental status changes, those admitted to a hospital during the preceding 3 months, or those who refused to participate in the survey $(\sim 25 \%$ of those enrolled) were excluded. To compare QOL of HD patients with that of a group of healthy referents, we used the database from the 2001 National Health Interview Survey, which was conducted by the National Health Research Institute and Bureau of Health Promotion, Department of Health, in Taiwan. ${ }^{11}$ In the National Health Interview Survey, 13,083 subjects completed the WHOQOL-BREF(TW) questionnaire. Of these subjects, 9,107 were healthy and had no known medical conditions. Two hundred eighty-three healthy subjects were age- $( \pm 10$ years), sex-, and education-matched and therefore considered similar to our HD patients.

\section{Tools of Investigation}

The WHOQOL-BREF(TW) consisted of 2 global items, G1 for overall QOL and G2 for general health, and 26 items in the physical, psychological, social relations, and environment domains. ${ }^{10,12}$ Specifically, there were 7,6 , 4, and 9 items in the physical, psychological, social relations, and environment domains, respectively. There were 2 items specific to Taiwan; Q27 and Q28 represented "being respected" and "eating food" as part of the social relations and environment domains, respectively. Application method, ref- erence time point, and item scoring were performed as described for the original WHOQOL-BREF. ${ }^{9}$ Global QOL score was calculated as the arithmetic mean of G1 and G2. Item scores ranged from 1 to 5 , and domain scores, from 4 to 20 , both on a Likert scale. A descriptor study was performed to make the scale interval-like. ${ }^{13}$

The symptom/problem ( $/ \mathrm{P})$ scale was used to show clinical sensitivity. The S/P scale of the Kidney Disease Quality-of-Life Short Form questionnaire ${ }^{14}$ consisted of 15 items pertaining to various symptoms or dialysis problems, such as headache, myalgia, dyspnea, pruritus, and so on. The descriptor, "not at all annoyed" to "most severely annoyed," ranged from 1 to 5 . S/P score was the mean of these 15 items and ranged from 1 to 5 , with a higher score indicating a greater number of symptoms and problems. Therefore, S/P score indicated the severity of HD conditions to some extent. $\mathrm{Kt} / \mathrm{V}$ and normalized protein catabolic rate $(\mathrm{nPCR})$ were important clinical variables and used in QOL determinant analysis. Kt/V was calculated by using Daugirdas' second formula. ${ }^{15}$ nPCR was calculated by using equations of Depner. $^{16}$

\section{Validation Analysis}

All data were analyzed using SAS (SAS Institute Inc, Cary, NC) and LISREL-SIMPLIS (Scientific Software International, Inc, Lincolnwood, IL) ${ }^{17}$ software, from which reliability and validity were assessed in 249 HD patients living in metropolitan Taipei. ${ }^{18,19}$ Reliability assessments included Cronbach's $\alpha^{20}$ and test-retest reliability. Validation assessments included content validity, criterion-related validity, concurrent validity, exploratory factor analysis, and confirmatory factor analysis of construct validity. ${ }^{20,21}$ The comparative fit index and nonnormed fit index were calculated to test goodness of fit ${ }^{20}$ for confirmatory factor analysis.

\section{Comparison of HD Patients With Healthy Referents}

HD patients were divided into 2 groups with different severity of $\mathrm{HD}$ condition ( $\mathrm{S} / \mathrm{P}<2.0$ and $\mathrm{S} / \mathrm{P} \geq 2.0$ ), and erythropoietin $(\mathrm{EPO})$ injection amounts per week $(<2,000$ and $\geq 2,000 \mathrm{IU} / \mathrm{wk}$ ). Next, QOL scores of 4 domains and global measures (G1, G2, and global QOL) were compared between HD patients and age-, sex-, and education-matched healthy referents.

\section{Analysis of QOL Determinants}

A multiple linear regression model was constructed by using summary scores of each facet/item and domain as dependent variables. Age, sex, marriage, and education were adopted as independent variables and controlled in this regression model. Religion, employment status in recent 1 year, Taipei/Keelung area, duration of HD therapy, and 8 clinical variables, including presence of comorbidity, Kt/V, hemoglobin ( $\mathrm{Hgb})$ level, hematocrit, albumin level, nPCR, S/P score, and EPO injection amounts per week, were considered independent variables for stepwise regression analysis. The adopted selection and exclusion criterion was $P$ less than 0.15 . 
Table 1. Comparisons of Frequencies of Demographic Characteristics Between Maintenance HD Patients and Age-, Sex-, and Education-Matched Healthy Referents

\begin{tabular}{|c|c|c|}
\hline Demographic Variable & $\begin{array}{l}\text { HD Patients } \\
(\mathrm{n}=376)\end{array}$ & $\begin{array}{l}\text { Healthy } \\
\text { Referents } \\
(\mathrm{n}=283)\end{array}$ \\
\hline \multicolumn{3}{|l|}{ Age (\%) } \\
\hline$<40 y$ & 11 & 15 \\
\hline 40 to $<50$ y & 16 & 22 \\
\hline$\geq 50 \mathrm{y}$ & 64 & 61 \\
\hline Male (\%) & 52 & 50 \\
\hline \multicolumn{3}{|l|}{ Education (\%) } \\
\hline Illiterate or primary & 54 & 46 \\
\hline Middle high & 16 & 19 \\
\hline High school & 17 & 22 \\
\hline College or graduate & 9 & 10 \\
\hline Married* ${ }^{*}$ & 68 & 78 \\
\hline Orient religious & 72 & 75 \\
\hline Employed within 1 y† & 19 & 61 \\
\hline Smoking† & 14 & 31 \\
\hline Drinking† & 7 & 32 \\
\hline With comorbidity $†$ & 42 & 0 \\
\hline S/P score $<2.0 \dagger(\%)$ & 76 & 100 \\
\hline \multicolumn{3}{|l|}{ Personal income (NTD $\ddagger)$} \\
\hline$<30,000$ & 86 & \\
\hline $30,000 \sim 60,000$ & 9 & \\
\hline$\geq 60,000$ & 3 & \\
\hline \multicolumn{3}{|l|}{ Family income (NTD $\ddagger)$} \\
\hline$<30,000$ & 57 & \\
\hline $30,000 \sim 60,000$ & 23 & \\
\hline$\geq 60,000$ & 14 & \\
\hline
\end{tabular}

Abbreviation: NTD, new Taiwan dollar.

${ }^{*} P<0.01$.

$\dagger P<0.001$

$\ddagger 1 \mathrm{NTD}=0.031$ US dollar.

\section{RESULTS}

\section{Subject Characteristics and Descriptive}

\section{Statistics}

All 513 patients completed the questionnaire. After deleting respondents who answered less than $80 \%$ ( 23 items) of 28 items or with illogical clinical values, 376 subjects were included for final analysis. Demographical data for these patients were compared with those for 283 healthy referents and are listed in Table 1. HD patients had lower percentages of employment, smoking, and drinking habit than healthy referents. For clinical variables, HD patients in this study had average values as follows: calculated $\mathrm{Kt} / \mathrm{V}, 1.66$ \pm 0.35 (SD); albumin, $3.85 \pm 0.39 \mathrm{~g} / \mathrm{dL}(38.5 \pm$ $3.9 \mathrm{~g} / \mathrm{L}) ; \mathrm{Hgb}, 10.0 \pm 1.4 \mathrm{~g} / \mathrm{dL}(99.6 \pm 13.8$ $\mathrm{g} / \mathrm{L})$; hematocrit, $30.8 \% \pm 4.3 \%$; calcium, 4.78 $\pm 0.48 \mathrm{mEq} / \mathrm{dL}(2.39 \pm 0.24 \mathrm{mmol} / \mathrm{dL})$; inorganic phosphorus, $1.64 \pm 0.50 \mathrm{mg} / \mathrm{dL}(0.53 \pm$ $0.16 \mathrm{mmol} / \mathrm{L}) ; \mathrm{EPO}, 2,536 \pm 3,456 \mathrm{IU} / \mathrm{wk}$; and $\mathrm{S} / \mathrm{P}$ score, $1.69 \pm 0.65$.

\section{Validation Verification of the WHOQOL-BREF(TW) in HD Patients}

Reliability and validity of the WHOQOLBREF(TW) in HD patients were verified and compared with those in a sample of the general population of Taiwan. ${ }^{12}$ As listed in Table 2, theWHOQOL-BREF(TW) was reliable and valid in these HD patients. Validation results were similar between our HD patients and the general population with the exception that test-retest reliability of the physical domain was only 0.48 . The comparative fit index and non-normed fit index were 0.92 and 0.90 and reached criteria, respectively.

QOL Measures of HD Patients and Comparison With Healthy Referents

All mean scores of 4 domains, except for environment, were significantly lower than those

Table 2. Comparison of the Reliability and Validity of the WHOQOL-BREF (TW) Between Maintenance HD Patients and the General Population

\begin{tabular}{|c|c|c|}
\hline Reliability and Validity & $\begin{array}{c}\text { HD } \\
\text { Patients } \\
(n=249)\end{array}$ & $\begin{array}{c}\text { General } \\
\text { Population } \\
\text { ( } n=1,068)\end{array}$ \\
\hline \multicolumn{3}{|l|}{ Reliability } \\
\hline Cronbach's $\alpha$ of domains & $0.70-0.80$ & $0.68-0.80$ \\
\hline \multicolumn{3}{|l|}{ Test-retest } \\
\hline Items & 一 & $0.41-0.79$ \\
\hline Domains & $0.48-0.82$ & $0.76-0.80$ \\
\hline \multicolumn{3}{|l|}{ Validity } \\
\hline \multicolumn{3}{|l|}{ Content } \\
\hline Item-corresponding domain & $0.44-0.79$ & $0.53-0.78$ \\
\hline Between domains & $0.41-0.71$ & $0.51-0.64$ \\
\hline \multicolumn{3}{|l|}{ Criterion-related } \\
\hline Item-global QOL & $0.12-0.49$ & $0.29-0.53$ \\
\hline Domain-G1 & $0.36-0.50$ & $0.39-0.53$ \\
\hline Domain-G2 & $0.36-0.53$ & $0.38-0.58$ \\
\hline \multicolumn{3}{|l|}{ Predictive (\%) } \\
\hline G1 & 28 & 33 \\
\hline G2 & 31 & 36 \\
\hline Global QOL & 38 & 45 \\
\hline \multicolumn{3}{|l|}{ Construct } \\
\hline $\begin{array}{l}\text { Exploratory factor analysis } \\
\text { (factors) }\end{array}$ & 4 & 4 \\
\hline $\begin{array}{l}\text { Confirmatory factor analysis: } \\
\text { comparative fit index }\end{array}$ & 0.92 & 0.90 \\
\hline
\end{tabular}

Abbreviations: G1, overall QOL; G2, general health. 
for age-, sex-, and education-matched healthy referents $(P<0.001)$. All mean scores of items in the physical, psychological, and social relations domains were lower than those of healthy referents $(P<0.01)$. In the environment domain, some were nearly the same, including "finance" and "information"; some QOL scores of HD patients were lower than those of healthy referents, including "safety" and "leisure" $(P<0.05)$; some were higher than those of healthy referents, including "physical environment," "health and social care availability," and "home environment" $(P<0.01)$. All QOL item scores in HD patients living in metropolitan Taipei were inferior to those in Keelung city, except for "negative feeling" from the psychological domain and "leisure" from the environment domain. In general, HD patients with more symptoms/problems or greater EPO injection amounts had lower QOL scores in all domains except for environment, as listed in Table 3. Findings also indicate that the WHOQOL-BREF(TW) may be useful in clinical assessment of subjective feelings.

\section{Determinants of $Q O L$}

After controlling for age, sex, education, and marriage, $\mathrm{Kt} / \mathrm{V}$ was not associated significantly with any QOL domains or items. Conversely, HD patients living in Keelung showed significantly higher scores in most QOL items than those in metropolitan Taipei. When HD patients had higher
S/P scores, their QOL scores were significantly worse in all except social relations domains and in all items in the physical domain, as well as many items of other domains $(P<0.05)$. Comorbidity with other diseases decreased QOL scores of "social support" and "being respected" in the social relations domain and "health care availability and quality" in the environment domain $(P<0.05)$. Increased Hgb level and lower EPO injection amounts seemed to have an independent positive effect on different QOL items. nPCR values showed significant associations with many items in the physical, psychological, and environment domains, indicating the potential for relating to QOL in HD patients. Employment significantly increased the scores of "health care availability and quality" and "transportation" in the environment domain $(P<$ $0.05)$. When duration of HD increased, the scores of the social relations domain decreased and corresponded to decreased scores in items of "sexual activity," "being respected," and "home condition."

\section{DISCUSSION}

In our verification analysis of the WHOQOLBREF(TW), test-retest reliability of the physical domain was lower, indicating that subjective physical QOL probably was not so stable in a duration of 4 to 8 weeks. All indicators of validity, listed in Table 2, show that the instrument is suitable for HD patients. Approximately $25 \%$ of enrolled patients refused to be interviewed. Many

Table 3. Comparisons Between Healthy Referents and HD Patients Stratified by More Than 2 Symptoms/Problems $(S / P \geq 2.0)$ and Different Injected EPO Doses

\begin{tabular}{|c|c|c|c|c|c|c|c|}
\hline \multirow[b]{2}{*}{ Variable } & \multirow[b]{2}{*}{$\begin{array}{l}\text { (a) Healthy } \\
\text { Referents } \\
(\mathrm{n}=283)\end{array}$} & \multicolumn{3}{|c|}{ Stratified by S/P } & \multicolumn{2}{|c|}{$\begin{array}{c}\text { Stratified by EPO Injection } \\
\text { Amount }\end{array}$} & \multirow[b]{2}{*}{$\begin{array}{c}\text { Tukey } \\
\text { (HSD) } \\
\text { Test }\end{array}$} \\
\hline & & $\begin{array}{c}\text { (b) } S / P<2.0 \\
(n=222)\end{array}$ & $\begin{array}{c}\text { (c) } S / P \geq 2.0 \\
(n=61)\end{array}$ & $\begin{array}{c}\text { Tukey (HSD) } \\
\text { Test }\end{array}$ & $\begin{array}{c}\text { (d) EPO } \\
<2,000 \\
(n=121)\end{array}$ & $\begin{array}{c}\text { (e) EPO } \\
\geq 2,000 \\
(n=120)\end{array}$ & \\
\hline Global QOL & $3.29 \pm 0.64$ & $3.24 \pm 0.82$ & $3.03 \pm 0.82$ & $a-c$ & $3.22 \pm 0.79$ & $3.16 \pm 0.85$ & \\
\hline G1: overall QOL & $3.52 \pm 0.72$ & $3.05 \pm 0.91$ & $2.59 \pm 0.90$ & $a-b, a-c, b-c$ & $3.03 \pm 0.93$ & $2.92 \pm 0.92$ & $a-d, a-e$ \\
\hline G2: general health & $3.40 \pm 0.58$ & $3.14 \pm 0.72$ & $2.81 \pm 0.76$ & $a-b, a-c, b-c$ & $3.13 \pm 0.74$ & $3.04 \pm 0.76$ & $a-d, a-e$ \\
\hline Physical domain & $15.01 \pm 2.10$ & $13.86 \pm 2.47$ & $11.04 \pm 3.13$ & $a-b, a-c, b-c$ & $13.64 \pm 2.81$ & $12.86 \pm 2.94$ & $\begin{array}{c}a-d, a-e \\
d-e\end{array}$ \\
\hline $\begin{array}{l}\text { Psychological } \\
\text { domain }\end{array}$ & $13.58 \pm 2.24$ & $12.52 \pm 2.83$ & $10.15 \pm 3.04$ & $a-b, a-c, b-c$ & $12.04 \pm 3.01$ & $11.91 \pm 3.16$ & $a-d, a-e$ \\
\hline $\begin{array}{l}\text { Social relations } \\
\text { domain }\end{array}$ & $14.07 \pm 1.96$ & $13.27 \pm 2.62$ & $12.34 \pm 2.56$ & $a-b, a-c, b-c$ & $13.49 \pm 2.56$ & $12.85 \pm 2.68$ & $a-d, a-e$ \\
\hline $\begin{array}{l}\text { Environment } \\
\text { domain }\end{array}$ & $13.05 \pm 2.00$ & $13.68 \pm 2.22$ & $12.15 \pm 2.27$ & $a-b, a-c, b-c$ & $13.54 \pm 2.12$ & $13.23 \pm 2.49$ & \\
\hline
\end{tabular}

NOTE. Only significance levels of $P<0.05$ under Tukey tests were listed for comparisons of different groups. Abbreviation: HSD, honestly significant difference. 
Table 4. Regression Coefficients for Determinants From Multiple Linear Regressions After Adjustment for Age, Sex, Education, and Marriage Status in 376 HD Patients

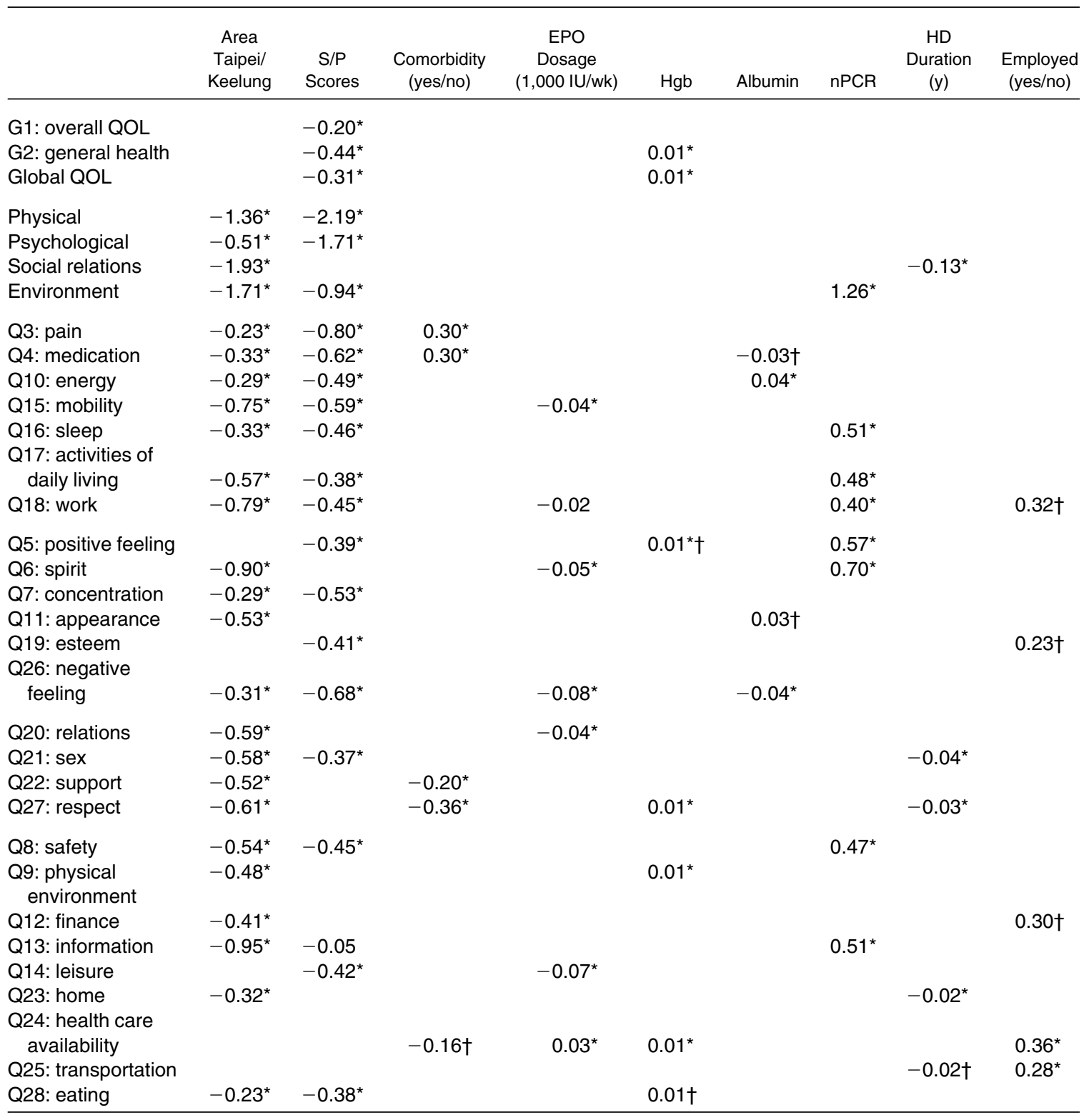

${ }^{*} P<0.05$.

$\dagger P<0.10$.

of them like to rest during the dialysis session, although they were in a grossly stable condition. Thus, QOL scores in our sample could be an overestimation. Compared with healthy referents, QOL scores of all except the environment domains, and most items, were significantly lower in our HD patients. Lower S/P scores, adequate EPO injection amounts, or greater nPCR seemed to correlate with higher QOL scores, as shown in
Tables 3 and 4. Findings corroborate the clinical validity of the WHOQOL-BREF(TW) instruments, also found in patients with other diseases, such as epilepsy and acquired immunodeficiency syndrome. ${ }^{22,23}$

The following determinants of QOL were reported in HD patients, including hematocrit, socioeconomic level, education level, dialysis schedule, and physical exercise as improving 
factors and comorbidity, diabetes mellitus, failed transplant, female sex, depression, and malnutrition as aggravating factors. ${ }^{7}$ To our limited knowledge, we are the first to apply multiple regression models to control potential confounding for assessing individual effects of various determinants for many QOL aspects in HD patients. Such models were useful for regular monitoring of clinical outcomes of HD patients. In our models, Kt/V was not the significant determinant of WHOQOL-BREF(TW) measures, which seemed consistent with QOL measured by means of the 36-Item Short-Form Health Survey. ${ }^{24} \mathrm{Kt} / \mathrm{V}$ was an indicator of dialysis dose and related to mortality of dialysis patients. ${ }^{25,26}$ However, dissociation between dialysis adequacy and $\mathrm{Kt} / \mathrm{V}$ was noted recently. ${ }^{27}$ Thus, relations among QOL, $\mathrm{Kt} / \mathrm{V}$, dialysis adequacy, and mortality remain to be clarified.

HD patients in metropolitan Taipei had lower QOL scores for most items than those living in Keelung city. Taipei is the capital of Taiwan. Patients in Taipei might have a higher standard of QOL and seemed subjectively more difficult to please. Thus, even after adjustment for age, sex, education, marriage status, and all other clinical indicators, there was a significant difference in QOL scores between HD subjects in the 2 cities. The average $\mathrm{Kt} / \mathrm{V}$ of HD patients living in metropolitan Taipei was almost the same as for those living in Keelung city $(1.69 \pm 0.37$ versus $1.65 \pm 0.34 ; P=0.48)$, which corroborated the hypothesis that such a difference might not result from different treatment dosages.

Both symptom/problem scores and comorbidity were reported to impact on QOL. ${ }^{28}$ However, $\mathrm{S} / \mathrm{P}$ scores were associated independently with most items and domains of QOL, whereas comorbidity showed less significant items. S/P inquires directly about concurrent subjective discomforts, but the presence of comorbidity was associated with only preexisting diseases or long-term illnesses. An alternative explanation might be that the presence of comorbid diseases made HD patients more accustomed to handling physical discomfort, as listed in Table 4.

In our multiple regression models, lower EPO injection amounts and greater Hgb level were associated with higher QOL scores in some items, as listed in Table 4. Both Hgb level and EPO dosage are variables related to the amount of red blood cells or severity of anemia. These 2 variables were reported to impact on several items of QOL. ${ }^{29-33}$ We incorporated both EPO dosage and Hgb level into our model fitting, which showed independent impacts, but of inverse direction, on QOL items. $\mathrm{Hgb}$ level was an outcome indicator that may connect closely with QOL, whereas EPO dosage was only a process indicator. Greater EPO dose might simply reflect more severe anemia and thus indicate poor QOL. Results listed in Table 4 show that the best fitted models for different items did not include both variables, which corroborated these explanations.

Both albumin level and calculated nPCR are outcome indicators of nutrition. ${ }^{34-37}$ Thus, both shared the same direction of effect on QOL, but did not show up in the same fitted regression model for individual items in Table 4. nPCR seemed to be incorporated into more models of WHOQOL items than albumin level. Taken together with these 2 variables, we conclude that nutrition had more impact on physical and psychological QOL, but not QOL of social relations.

The longer patients received HD, the worse they felt subjectively about sexual life and the extent of being respected. Improving these aspects of social relations would be crucial to improve the QOL of patients with ESRD in the future because survival of dialysis patients has much improved in recent decades.

The current study leads us to 3 conclusions: (1) the WHOQOL-BREF(TW) is valid for HD patients; (2) HD has a negative impact on many QOL measures with various degrees, especially in patients with more severe disease with greater S/P scores; and (3) Hgb level, nPCR, and symptoms/problems of HD patients were prominent and clinically manageable determinants of QOL in HD patients.

\section{ACKNOWLEDGMENT}

The authors thank Drs Max Wu, Jin Yang, Shih-Jen Gao, Wei-An Hsu, Lien-Jei Yang, Shau-I Liu, and Jin-Hsiung Fang for their kind permission and help to enroll patients.

\section{REFERENCES}

1. Fayers PM, Machin D: Quality of Life. Assessment, Analysis and Interpretation. West Sussex, England, Wiley, 2000, pp 7-14

2. Fink JC: Current outcomes for dialysis patients, in Henrich WL (ed): Principle and Practice of Dialysis (ed 3). Philadelphia, PA, Lippincott Williams \& Wilkins, 2004, pp 662-672 
3. Hwang SJ, Yang WC, and the Dialysis Surveillance Committee, TSN: 1999 National Dialysis Surveillance in Taiwan. Acta Nephrol 14:139-228, 2000

4. Salzburg DJ, Hanes DS: Quality of life and rehabilitation in dialysis patients, in Henrich WL (ed): Principle and Practice of Dialysis (ed 3). Philadelphia, PA, Lippincott Williams \& Wilkins, 2004, pp 662-672

5. Szabo S: The World Health Organization Quality of Life (WHOQOL) assessment instrument, in Spiker B (ed): Quality of Life and Pharmacoeconomics in Clinical Trials. Philadelphia, PA, Lippincott-Raven, 1996, pp 355-362

6. The WHOQOL Group: Development of the World Health Organization WHOQOL-BREF assessment. Psychol Med 28:551-558, 1998

7. Skevington SM, Lotfy M, O'Connell KA: The World Health Organization WHOQOL-BREF quality of life assessment: Psychometric properties and results of the international field trial. A Report from the WHOQOL Group. Qual Life Res 13:299-310, 2004

8. Valderrabano F, Jofre R, Lopez-Gomez JM. Quality of life in end-stage renal disease patients. Am J Kidney Dis 38:443-464, 2001

9. Edgell ET, Coons SJ, Carter WB, et al: A review of health-related quality-of-life measures used in end-stage renal disease. Clin Ther 18:887-937, 1996

10. The WHOQOL-Taiwan Group: The User's Manual of the Development of the WHOQOL-BREF Taiwan Version (ed 1 revised). Taipei, Taiwan, National Taiwan University, 2001

11. Shih YT, Chang HY, Le KH, Lin MC, Su WC: Introduction to the National Health Interview Survey (NHIS). Taiwan Natl Health Interview Survey Res Brief 1:1-8, 2002

12. Yao G, Chung CW, Yu CF, Wang JD: Development and verification of validity and reliability of the WHOQOLBREF Taiwan version. J Formos Med Assoc 101:342-351, 2002

13. Lin MR, Yao G, Hung JS, Wang JD: Selection of descriptors in WHOQOL, Taiwan version. Chinese J Public Health (Taipei) 18:262-270, 1999

14. Hays RD, Kallich JD, Mapes DL, Coons SJ, Amin N, Carter WB: Kidney Disease Quality of Life Short Form $\left(\mathrm{KDQOL}_{-} \mathrm{SF}^{\mathrm{TM}}\right)$, version 1.3: A Manual for Use and Scoring. Santa Monica, CA, Rand, 1994

15. Daugirdus JT, Van Stone JC: Physiological principles and urea kinetic modeling, in Daugirdus JT, Blake PG, Ing TS (eds): Handbook of Dialysis (ed 3). Philadelphia, PA, Lippincott Williams \& Wilkins, 2001, pp 15-45

16. Depner TA: Quantifying hemodialysis. Am J Nephrol 16:17-28, 1996

17. Schumacker RE, Lomax RG: A Beginner's Guide to Structural Equation Modeling. Hillsdale, NJ, Erlbaum, 1996, pp 8-9, 119-137

18. Nunally JC: Psychometric Theory. New York, NY, McGraw-Hill, 1967, p 226

19. Bonomi AE, Patric DL, Bushnell DM, Matrin M: Validation of the World Health Organization Quality of Life (WHOQOL) instrument. J Clin Epidemiol 53:1-12, 2000

20. Hatcher L: A Step-by-Step Approach to Using the SAS System for Factor Analysis and Structural Equation Modeling. Cary, NC, SAS Institute, 1994, pp 129-140, 249-342
21. Hays RD, Anderson RT, Revicki T: Assessing reliability and validity of measurement in clinical trial, in Staquet MJ, Hay RD, Fayers PM (eds): Quality of Life Assessment in Clinical Trials. Method and Practice. New York, NY, Oxford, 1998, pp 174-175

22. Liou HH, Chen RC, Chen CC, Chiu MJ, Chang YY, Wang JD: Health related quality of life in adult patients with epilepsy compared with a general reference population in Taiwan. Epilepsy Res 64:151-159, 2005

23. Hsiung PC, Fang CT, Chang YY, Chen MY, Wang JD: Comparison of WHOQOL-BREF and SF-36 in patients with HIV infection. Qual Life Res 14:141-150, 2005

24. Moreno F, Lopez Gomez JM, Sanz Guajardo D, Jofre R, Valderrabano F: The Spanish Cooperative Renal Patients Quality of Life Study Group: Quality of life in dialysis patients. A Spanish multicenter study. Nephrol Dial Transplant 11:S125-S129, 1996 (suppl 2)

25. Gotch FA, Sargent JA: A mechanistic analysis of the National Cooperative Dialysis Study (NCDS). Kidney Int 28:526-534, 1985

26. Held PJ, Port FK, Wolfe RA, et al: The dose of dialysis and patient mortality. Kidney Int 50:550-556, 1996

27. Vanholder R, DeSmet R, Lesaffer G: Dissociation between dialysis adequacy and Kt/V. Semin Dial 15:1-7, 2002

28. Rocco MV, Gassman JJ, Wang SR, Kaplan RM: Cross-sectional study of quality of life and symptoms in chronic renal disease patients: The Modification of Diet in Renal Disease Study. Am J Kidney Dis 29:888-896, 1997

29. Fishbane S, Paganini EP: Hematological abnormalities, in Daugirdus JT, Blake PG, Ing TS (eds): Handbook of Dialysis (ed 3). Philadelphia, PA, Lippincott Williams \& Wilkins, 2001, pp 477-494

30. MacMahon LP, Mason K, Skinner SL: Effects of haemoglobin normalization on quality of life and cardiovascular parameters in end-stage renal failure. Nephrol Dial Transplant 15:1425-1430, 2000

31. Moreno F, Sanz-Guarjado D, Lopez-Gomez JM, Jofre R, Valderrabano F: Increasing the hematocrit has a beneficial effect on quality of life and is safe in selected hemodialysis patients. J Am Soc Nephrol 11:335-342, 2000

32. Eschbach JW, Glenny R, Robetson T: Normalizing the hematocrit in hemodialysis patients with EPO improves quality of life and is safe. J Am Soc Nephrol 4:425A, 1993 (abstr)

33. Ahlmen J: Quality of life of the dialysis patient, in Horl WH, Koch KM, Lindsay RM, Ronco C, Winchester JF (eds): Replacement of Renal Function by Dialysis (ed 5). Dordrecht, The Netherlands, Kluwer, 2004, pp 1315-1331

34. Marckmann P: Nutritional status of patients on hemodialysis and peritoneal dialysis. Clin Nephrol 29:75-78, 1988

35. O'Connor AS, Wish JB: Hemodialysis adequacy and the timing of dialysis initiation, in Henrich WL (ed): Principle and Practice of Dialysis (ed 3). Philadelphia, PA, Lippincott Williams \& Wilkins, 2004, pp 115-116

36. Kaysen GA, Stevenson FT, Depner TA: Determinants of albumin concentration in hemodialysis patients. Am J Kidney Dis 29:658-668, 1997

37. Rocco MV, Blumenkrantz MJ: Nutrition, in Daugirdus JT, Blake PG, Ing TS (eds): Handbook of Dialysis (ed 3). Philadelphia, PA, Lippincott Williams \& Wilkins, 2001, pp 420-445 